\title{
REPRESENTAÇÕES SOCIAIS DE PROFISSIONAIS DE NÚCLEOS DE APOIO À SAÚDE DA FAMÍLIA SOBRE INTERDISCIPLINARIDADE
}

\author{
SOCIAL REPRESENTATIONS OF PROFESSIONALS CENTERS OF SUPPORT FOR FAMILY HEALTH ON \\ INTERDISCIPLINARITY
}

\author{
REPRESENTACIONES SOCIALES DE PROFESIONALES DE NÚCLEOS DE APOYO A LA SALUD DE LA \\ FAMILIA SOBRE INTERDISCIPLINARIDAD
}

\author{
Herta Maria Castelo Branco Ribeiro ${ }^{1}$ \\ Zeni Carvalho Lamy ${ }^{2}$ \\ Liberata Campos Coimbra ${ }^{3}$ \\ Lívia Janine Leda Fonseca Rocha ${ }^{4}$ \\ Dorlene Maria Cardoso de Aquino ${ }^{5}$ \\ Nair Portela Silva Coutinho ${ }^{6}$ \\ Liduina Farias Almeida da Costa $^{7}$
}

Resumo Este trabalho objetivou analisar as representações sociais de profissionais de Núcleos de Apoio à Saúde da Família da Secretaria Executiva Regional IV, em Fortaleza, Ceará, sobre a interdisciplinaridade em seu cotidiano do trabalho. Trata-se de estudo qualitativo, utilizando como técnicas de coleta de dados a observação participante e entrevistas semiestruturadas com 15 profissionais e coordenadores. Na definição da amostra, utilizou o critério de saturação teórica; na análise, a hermenêutica de profundidade. As representações foram organizadas nas seguintes categorias: processo em construção, realização de atividades conjuntas e resultado do compromisso das equipes. Os caminhos percorridos apontam para uma interdisciplinaridade ainda embrionária, resultado de inúmeros fatores intrínsecos e extrínsecos ao próprio grupo. As dificuldades oriundas das cobranças de produtividade pela gestão, o planejamento incipiente, o processo de formação que incorpora pouco essa perspectiva e a precarização das relações de trabalho são elementos que impactam negativamente na realização de práticas interdisciplinares. As falas denotam inúmeras possibilidades que se constroem no campo da saúde e inspiram a superação da fragmentação dos múltiplos saberes que atuam na perspectiva coletiva.

Palavras-chave atenção primária à saúde; núcleo de apoio à saúde da família; interdisciplinaridade; representações sociais.
Abstract This study aimed to analyze the social representations of professionals working at Family Health Support Centers operating under the 4th Regional Executive Department, in Fortaleza, state of Ceará, Brazil, with regard to interdisciplinarity in their daily work. It is a qualitative study, which used participant observation techniques and semi-structured interviews with 15 professionals and coordinators to collect data. The theoretical saturation criterion was used in the sample definition. The analysis used the in-depth hermeneutics. The representations were organized in these categories: Process under construction, undertaking joint activities, and outcome of the teams' commitment. The paths taken point to yet embryonic interdisciplinarity, the outcome of numerous factors that are intrinsic and extrinsic to the group itself. The difficulties arising from pressure imposed by management for productivity, the incipient planning, the training process that incorporates some of this perspective, and the precarious labor relations are elements that have a negative impact on the performance of interdisciplinary practices. The speeches denote endless possibilities that are built in the field of health and inspire overcoming the fragmentation of multiple knowledge that works in the collective perspective. Keywords primary health care; family health support center; interdisciplinarity; social representations. 


\section{Introdução}

Na produção do trabalho em saúde é o trabalho coletivo, de caráter interdisciplinar, que se coloca como elemento propiciador e realizador das práticas educativas, principalmente no contexto da consolidação do Sistema Único de Saúde (SUS) e em especial na Atenção Primária em Saúde (APS). Uma compreensão diferenciada dos modelos tecnoassistenciais vai impelir a construção de dispositivos de saúde que favoreçam o desenvolvimento das ações centradas na família, considerando como prioritárias as ações de promoção da saúde.

O Programa de Saúde da Família (PSF) vai se originar a partir desse entendimento no ano de 1994, com o propósito de "superação de um modelo de assistência à saúde, responsável pela 'ineficiência do setor'; 'insatisfação da população'; 'desqualificação profissional'; 'iniquidades'”' (Franco e Merhy, 2007). Constituir-se-á resposta à crítica ao modelo assistencial centrado em uma visão biologicista do processo saúde-doença.

Para o desenvolvimento dessa proposta, baseada principalmente em metodologias coletivas, à atuação profissional é imposta a necessidade concreta de uma atitude interdisciplinar consciente que possibilite atingir os objetivos propostos de atenção integral à saúde das pessoas. Isso requer reflexão e esforço coletivo das equipes envolvidas, na perspectiva de romper com o "conhecimento fragmentado pelas especializações disciplinares originadas no século $\mathrm{XX}^{\prime \prime}$, que impossibilitam a compreensão do fenômeno em sua complexidade (Morin, 2011a).

As equipes do PSF são compostas por profissionais de especialidades distintas e têm suas funções normatizadas pelo Ministério da Saúde, configurando como ação estratégica para a construção do novo modelo de saúde, evoluindo assim para Estratégia Saúde da Família (ESF) em 1998. Muito é produzido acerca das diretrizes de trabalho no campo da ESF, que aos poucos começará a demandar novos saberes, necessitando da atuação de diferentes categorias profissionais. Em sua proposta, a ESF tinha como suporte as áreas de medicina, enfermagem e odontologia, além dos profissionais de nível médio e elementar. Em 2011, a Política Nacional de Atenção Básica (PNAB) definiu e regulamentou os Núcleos de Apoio à Saúde da Família (NASF). Os NASF são dispositivos de suporte à ESF criados ainda em 2008, mediante a portaria GM n. 154, de 24 de janeiro, com o objetivo de apoiar a inserção da ESF na rede de serviços, aumentando abrangência, resolutividade e ampliação das ações da APS no Brasil. Desde sua gênese já lhe é imposta a necessária articulação no sentido de agir efetivamente em conjunto com os profissionais das Equipes de Saúde da Família, a partir do ingresso de novos saberes na ESF: 
O NASF deve atuar dentro de algumas diretrizes relativas à APS, a saber: ação interdisciplinar e intersetorial; educação permanente em saúde dos profissionais e da população; desenvolvimento da noção de território; integralidade, participação social, educação popular; promoção da saúde e humanização (Brasil, 2010, p.7).

As equipes que compõem os NASF são formadas por profissionais de diferentes áreas do conhecimento e objetivam apoiar a ESF, integrando suas ações, compartilhando saberes e práticas em saúde, tendo como elemento principal de atuação o apoio matricial (Brasil, 2010). Sua constituição não é 'física', ou seja, não há uma unidade predial independente para sua atuação. A intervenção do NASF deve partir de demandas identificadas em conjunto com as equipes e atua de forma integrada à rede, articulando o cuidado aos diversos dispositivos de apoio, inseridos na saúde, assistência, previdência, educação, entre outros. Pode ser desenvolvida nas unidades de saúde, academias de saúde, escolas ou outro ponto do território.

O trabalho do NASF requer um nível de integração bastante fortalecido, pela necessidade imposta por meio da PNAB de

revisão da prática do encaminhamento com base nos processos de referência e contrarreferência, ampliando para um processo de compartilhamento de casos e acompanhamento longitudinal de responsabilidade das equipes de atenção básica, atuando no fortalecimento de seus princípios e no papel de coordenação do cuidado nas redes de atenção à saúde (Brasil, 2011).

Uma atuação que exige um esforço para contribuir com a

integralidade do cuidado aos usuários do SUS a partir da discussão de casos, interconsulta, construção conjunta de projetos terapêuticos, educação permanente, intervenções no território e na saúde de grupos populacionais e da coletividade, ações intersetoriais, ações de prevenção e promoção da saúde, discussão do processo de trabalho das equipes etc. (Brasil, 2011).

Nesse sentido, as “Diretrizes do NASF: Núcleo de Apoio à Saúde da Família" (Brasil, 2010) propõem para a organização do processo de trabalho dos NASF a corresponsabilização e o compartilhamento de múltiplos saberes, numa perspectiva de capacitação e envolvimento de todos os profissionais da ESF, com a concretização do apoio matricial e da efetivação do cuidado. No campo da saúde, o produto do trabalho é o cuidado, produzido durante o processo de trabalho, que sofre as determinações das condições postas nessa produção. Esse mesmo documento aponta que "a maioria dos profissionais de saúde não tem formação básica que valorize o trabalho em equipe". 
Assim, a interdisciplinaridade coloca-se como nosso objeto de investigação no âmbito dos NASF. O referencial teórico que deu suporte à discussão da interdisciplinaridade foi amparado por autores como Japiassu (1976); Fazenda (2007, 2012); Vasconcelos (2002); Severino (2006); e Morin (2011a, 201 lb, 2012). Aportamo-nos em Japiassu (1976), que situa a interdisciplinaridade como um dos níveis possíveis de cooperação entre as disciplinas, considerando-a como um sistema de dois níveis e objetivos múltiplos, com a cooperação coordenada a partir de finalidades estabelecidas. As relações entre disciplinas objetivam resultados comuns.

Para Japiassu, a interdisciplinaridade torna-se uma exigência, impondo a cada especialista que transcenda sua própria especialidade, reconheça seus limites e acolha as contribuições inerentes a outras disciplinas. É a epistemologia da complementariedade, da convergência, que substituiria a da dissociação. Atribuímos a essa reflexão importância ímpar, no sentido de romper com as práticas fragmentadas.

Diante do exposto é necessário situar que muitas práticas profissionais fragmentadas em nível do pensamento justificam ou questionam as dificuldades apresentadas no âmbito das vivências interdisciplinares. O objetivo desta pesquisa foi analisar as representações sociais sobre a interdisciplinaridade no cotidiano das práticas dos profissionais dos NASF. A proposta não é a de promoção do consenso, mas situa-se na partilha desses saberes, em uma perspectiva de alteridade, ou seja, quando uma cultura não tem como objetivo a extinção de uma outra. A alteridade implica que um indivíduo seja capaz de se colocar no lugar do outro, em uma relação baseada no diálogo e valorização das diferenças existentes (Lévinas, 1997).

Segundo Minayo (2013), representações sociais é um termo filosófico que significa a reprodução de uma percepção anterior ao conteúdo do pensamento. Na filosofia e na sociologia clássicas são encontradas as bases do conceito de representações sociais, atualmente bastante discutido no âmbito da psicologia social. Vale ressaltar que essa teoria encontra-se em expansão em diversos campos da ciência, indicando um caráter eminentemente interdisciplinar. O autor acrescenta que "se trata de uma teoria que investiga e explica a relação recíproca entre indivíduo e sociedade" (Ferreira, 2008, p. 123).

É no contexto da comunicação e dos sentidos, produzido nas relações sociais, que se encontram as representações, expressas em gestos, falas, sentimentos, pensamentos e ações, elementos que dão forma ao nosso objeto de pesquisa. O propósito de discutir as representações sociais sobre a interdisciplinaridade justifica-se pela necessidade de subsidiar perspectivas de transformação de uma realidade em outra melhorada, a partir da reflexão. 


\section{Percurso metodológico}

Trata-se de pesquisa qualitativa 8 realizada no município de Fortaleza, Ceará, entre os meses de agosto e dezembro de 2013. A capital está dividida em seis áreas regionais. Cada região é administrada por uma Secretaria Executiva Regional (SER). A área selecionada para a pesquisa foi a SER IV. O número total de equipes de NASF no município é 11, segundo o Cadastro Nacional de Estabelecimentos de Saúde (BRASIL, 2013). Como critérios de inclusão para a realização da pesquisa na SER IV, consideramos o contingente populacional significativo (305 mil habitantes) e a rede de saúde estruturada por 12 unidades de atendimento básico (36 Equipes de Saúde da Família e três NASF), além de três Centros de Atenção Psicossocial e um Centro de Atendimento à Criança. A Regional possui ainda a segunda maior emergência do Estado do Ceará, o Frotinha da Parangaba, que realiza uma média de 16 mil atendimentos por mês.

Participaram deste estudo 15 profissionais das equipes que compõem os NASF (assistentes sociais, psicólogos, terapeutas ocupacionais, farmacêuticos, fisioterapeutas, fonoaudiólogas); quatro gestores envolvidos diretamente nas ações promovidas pelas referidas equipes (coordenadoras dos NASF e da educação permanente); e dois profissionais dos Centros de Saúde da Família. As equipes dos NASF entrevistadas são compostas pelas seguintes categorias profissionais:

- NASF 41: 3 assistentes sociais; 1 farmacêutica; 1 fisioterapeuta e 1 psicóloga;

- NASF 42: 1 assistente social; 1 farmacêutica; 1 fonoaudióloga; 1 psicóloga; 1 fisioterapeuta;

- NASF 43: 2 assistentes sociais; 1 terapeuta ocupacional; 1 farmacêutica e 1 fisioterapeuta.

A totalidade desses profissionais foi inserida nos NASF em julho/2013, a partir de uma seleção pública de vínculo temporário (dois anos) com uma carga horária de vinte horas semanais, fato que é apresentado recorrentemente como elemento de instabilidade e precarização do trabalho profissional. As equipes anteriores (que possuíam o mesmo regime de contratação) foram dissolvidas após a transição do governo municipal.

Os profissionais entrevistados que atuam na gestão dos NASF e da educação permanente possuem experiência na ESF e especializações em áreas afins. Foram informantes a coordenadora dos NASF e a coordenadora da educação permanente da SER IV. A coordenadora dos NASF esteve como fisioterapeuta em uma equipe de NASF na gestão anterior e possui especialização em Saúde da Família e Comunidade.

Quanto à coleta de dados, utilizou-se a observação participante ou em profundidade, cujos relatos foram anotados em diário de campo. Além de 
visitas institucionais, a observação participante ocorreu em cinco encontros de capacitação promovidos pelos residentes do Programa de Residência Multiprofissional em Saúde da Família e Comunidade da Secretaria Municipal de Saúde do estado do Ceará, para as equipes dos NASF, com os temas: O Lugar do NASF; Territorialização como Pressuposto para a Organização dos Processos de Trabalho da ESF; Interdisciplinaridade e Colaboração Interprofissional; Visita Domiciliar e Atendimento Conjunto e Práticas Grupais na APS.

Realizaram-se ainda entrevistas semiestruturadas (gravadas e transcritas) com os profissionais e gestores. Uma amostra representativa foi constituída mediante processo de saturação teórica, considerando-se a interrupção da coleta de dados, ao constatarmos que novos elementos não eram mais depreendidos a partir do campo de observação (Fontanella e Magdaleno Junior, 2012).

Os dados foram analisados a partir da hermenêutica de profundidade, considerando os três passos sugeridos por Demo (2012): contextualização sócio-histórica, análise formal e interpretação, orientada pelos referenciais teóricos. O projeto de pesquisa foi aprovado no Comitê de Ética em Pesquisa da Universidade Estadual do Ceará (protocolo n. 400.974/2013). Os participantes foram identificados nas entrevistas por meio de uma numeração, com a profissão e o local de atuação (SER [para gestores], NASF, Unidade Básica de Saúde [UBS]). Os dados coletados na observação participante e registrados em diário de campo foram identificados como DC.

\section{Resultados e discussão}

A partir da observação e de estabelecermos diálogos com as falas dos sujeitos, verificamos que há elementos de entrave às práticas efetivamente interdisciplinares. A estrutura organizacional do NASF prevê uma subordinação simultânea à coordenadora dos NASF, mas também às coordenadoras das UBS em que os profissionais atuam, os quais precisam atender a demandas das chefias. As relações de poder postas interferem no cotidiano das práticas.

Além desse destaque, outra questão que se conecta com o processo de trabalho é latente e alvo de críticas dos profissionais, posto que o desenho estabelecido para a atuação dos NASF não possibilita o estabelecimento de vínculos institucionais e comunitários, bem como insere-se em um contexto de precarização estrutural, o que impacta diretamente a organização das atividades e o alcance dos objetivos estabelecidos em sua implantação. Na SER IV cada equipe de NASF acompanha cerca de 12 Equipes de Saúde da Família, contrariando a portaria GM/3.124, de 28 de dezembro de 2012, que reduz para nove o número máximo de equipes de saúde a ser vinculada a cada NASF (Brasil, 2012). 
Nós infelizmente não temos estrutura pra trabalho, não temos assim apoio nenhum da prefeitura, da Regional, nada. Na verdade, nós temos que trabalhar a velha cota, né, temos que tirar dinheiro do bolso para que as ações aconteçam. Mas nós fazemos isso porque nós queremos que as coisas aconteçam, queremos realmente mostrar o que é o NASF. Se o NASF for estruturado, ele sem estrutura tá atuando bem, a gente tá conseguindo aumentar a resolutividade da Saúde da Família. E particularmente o trabalho tá bom, mas falta muito, tem muito a desejar ainda por conta da estrutura que nós não temos. Não temos apoio nenhum, não temos sala pra trabalhar, não temos material pra trabalhar, infelizmente. Carro disponível tem que tá dividindo muito com a Estratégia Saúde da Família. E na verdade, assim, falta recurso pra gente poder fazer territorialização, poder trabalhar com os agentes, dar realmente, trabalhar realmente os agentes principais, os protagonistas, que são justamente as instituições, as associações de moradores, os líderes comunitários. A gente não tem como atuar com esse público ( 1 - Assistente Social NASF).

Nós temos dificuldade de ter essa Roda de Gestão por conta de horários, né? Cada uma trabalha em outra área, em outro trabalho, em outro local, então fica difícil nós nos encontrarmos e programar alguma coisa $(2$ - Terapeuta Ocupacional NASF).

Por exemplo, se você tem um Núcleo, pra se dividir entre duas unidades, tudo bem. Mas entre quatro, cinco? Quanto tempo ele vai ter pra dispor dentro da unidade? Quando a gente consegue muitas vezes se encontrar é uma vez no mês. Pra bater a agenda de um (7 - Enfermeira UBS).

A entrada no NASF foi meio de 'paraquedas'. Como conhecer melhor já que é exigido ação? (Fisioterapeuta NASF - DC).

As equipes [de Saúde da Família] não estavam preparadas quando o NASF chegou. Cada dia estamos em um posto diferente, há o comprometimento da continuidade (Psicóloga NASF - DC).

Krug et al. (2010), ao analisarem o processo de trabalho na ESF, evidenciam dificuldades no estabelecimento de um plano de ação, que fica comprometido pelo acúmulo de tarefas e não se chega a pensar estrategicamente as tomadas de decisões, com informações, planejamento e organização resolutivos. No caso em análise, que possui planejamento comprometido devido à imediaticidade das demandas e à ausência de compreensão do papel do NASF por parte das equipes, tais dificuldades acentuam-se.

Pensar a saúde é pensar numa construção não linear e considerar que não há um produto final, mas que o cuidado, produto dessa ação, perpassa todas as etapas do processo de trabalho. 
Refletir sobre o processo de trabalho na saúde é compreender como se organiza o trabalho para uma atividade produtiva. Os elementos constituintes do processo de trabalho, o objeto de trabalho, são os diversos saberes, os instrumentos e o trabalho em si (Reis e David, 2010). Entende-se que o elemento de destaque no processo de trabalho na saúde é o trabalho vivo. É o ser humano (trabalhador) no centro da produção de cuidado, com a finalidade de atender às necessidades de outro ser humano.

À luz da observação participante e das representações expressas na riqueza das falas dos sujeitos, foi possível desvelar elementos extrínsecos e intrínsecos ao grupo de profissionais. Relatou-se quanto é difícil o exercício do trabalho interdisciplinar e a própria compreensão do que constitui essa 'unidade de saber'. Fica claro, tanto nas atividades desenvolvidas como na linguagem dos sujeitos nas entrevistas, que há uma busca pela interdisciplinaridade e que o processo de trabalho perpassa todas as representações, interferindo tanto nas percepções quanto nas práticas dos profissionais dos NASF.

A partir desse percurso, depreendem-se três categorias como representações sociais da interdisciplinaridade: interdisciplinaridade como processo em construção; interdisciplinaridade como a realização de atividades em conjunto; interdisciplinaridade como resultado do compromisso profissional.

\title{
Interdisciplinaridade como processo em construção
}

\begin{abstract}
Ainda muito fraca (a interdisciplinaridade). Ainda precisando ser resgatada. Não é nem resgatada, porque começou agora, mas assim, mostrar que veio com esse princípio, da interdisciplinaridade, a intersetorialidade, com a multiprofissional, porque existe muito essa questão de se esconder o tempo todo. Ou então de se anular. Não só do NASF, mas dos próprios profissionais. Que é aquela história, quem é o apoiado e quem é o apoiador? Aonde é que eu tô nesse meio de campo? A gente tem que definir realmente papéis no território, na equipe e nas rodas de conversa ( 5 - Gestor - SER).
\end{abstract}

Compreender como se dá a interdisciplinaridade no âmbito do NASF nos remete à construção histórica da própria política e da formação profissional dos diferentes profissionais dessas equipes. Nesse sentido, é importante assegurar que, apesar de a formação para o trabalho interdisciplinar ser elemento constitutivo dos currículos de graduação da área de saúde (Rossoni e Lampert, 2004), a expressão da interdisciplinaridade no cotidiano das práticas paradoxalmente não é o resultado de um processo formador que a contemple como exigência para esse campo específico de atuação. Mesmo sendo frequente o discurso da interdisciplinaridade, ela ainda é permeada de vieses e interpretações que se encontram em nível do pensamento ou ações e denotam que é um processo em construção, cuja resistência acontece 
devido à formação profissional que privilegia a especialização e o próprio modo de pensar individualista contemporâneo, percepção aparente apenas quando as ideias e práticas são observadas e esmiuçadas. As falas a seguir, colhidas na observação de uma das oficinas e em entrevista, exemplificam a nossa análise:

Sabemos que é preciso desconstruir a ideia da consulta individualizada (realizada por um único profissional). Todavia, a ideia de uma prática que se pareça com a outra parece que desqualifica a ação coletiva ( 1 - Assistente Social - NASF).

É quase uma crise de identidade. Passamos a ser 'profissional de saúde'. Acho que, se a formação preconizasse a interdisciplinaridade, não haveria esse choque com a realidade. Não pensamos assim ( 8 - Psicóloga - NASF).

A compreensão ainda ambígua das atribuições dos profissionais do NASF no contexto do trabalho interdisciplinar se apresenta recorrente no contexto das práticas não só destes, mas estende-se aos demais profissionais da ESF que demandam atendimentos específicos de 'fisioterapia', 'terapia ocupacional', 'serviço social', aguardando um parecer do 'especialista' e uma intervenção eficaz no problema (muitas vezes dissociado do contexto ao qual está inserido). O interdisciplinar, proposto para o NASF em suas Diretrizes Básicas (Brasil, 2010), por meio de projetos terapêuticos singulares, interconsulta, visitas domiciliares, entre outras práticas, requer esforço da equipe para implementação e é o desafio que começa a ficar claro no interior das discussões das equipes. A equipe manifestou que a maior parte dessas atividades não são realizadas ainda e, no caso das visitas domiciliares, é privilegiada a abordagem do especialista, demandado pelos profissionais da ESF.

A impressão que tenho é que as equipes [de Saúde da Família] consideram-nos apenas como técnicos isolados: se há alguém chorando, chamem a psicóloga; se tem problema de obesidade, precisa de uma nutricionista. São os nossos estereótipos (8- Psicóloga - NASF).

Segundo Japiassu (1976, p. 14), “a ciência é a consciência do mundo. A doença do mundo moderno corresponde a um fracasso, a uma demissão do saber". Para o autor, a multiplicação de cientistas não representa um progresso do conhecimento, mas o sintoma de uma regressão, considerando que, ao se ampliar a diversificação, se perde o contato com a realidade humana. Ele propõe uma nova epistemologia, que ultrapassaria as ciências individualizadas, mas seria fruto de uma renúncia ao confinamento das especialidades e procuraria a "restauração das significações humanas do conhecimento" (Japiassu, 1976, p. 14). 
Coadunando com esse pensamento, ao se referir à questão do conhecimento, Morin (2011a) sinaliza a necessidade de uma reforma do pensamento fragmentado, que passe a compreender a complexidade, modificando a nossa forma de organizar o conhecimento.

(...) existe inadequação cada vez mais ampla, profunda e grave entre, de um lado, os saberes desunidos, divididos, compartimentados e, outro lado, as realidades ou os problemas cada vez mais multidisciplinares, transversais, multidimensionais, transnacionais, globais e planetários (Morin, 2011a, p. 33).

Souza (2013), ao estudar o processo de construção dos NASF no Estado do Ceará, reitera que o objeto do trabalho em saúde é histórico e socialmente construído. No caso dos NASF, implantados para compartilhar saberes e práticas com os profissionais da ESF, sua atuação tem como eixo fundante do processo de trabalho a interdisciplinaridade das ações. Essa compreensão recoloca o desafio de modificar a relação e privilegia, ainda, o biológico, a doença, a especialização. Segundo Leite e Veloso (2008), o trabalho em equipe é essencial no processo de inversão dos modelos de atenção à saúde, em que a horizontalidade nas relações começa a construir o cotidiano do trabalho.

Nesse sentido, conhecer isoladamente não é mais suficiente, mas torna-se necessária a compreensão do contexto para que o sentido das coisas fique verdadeiramente evidenciado. Morin (201 lb) vai categorizar o global, mais especificamente a relação entre o todo e as partes. "O todo tem qualidades ou propriedades que são encontradas nas partes, se estas estiverem isoladas umas das outras, e certas qualidades ou propriedades das partes podem ser inibidas pelas restrições provenientes do todo" (Morin, $2011 \mathrm{~b}$, p.35).

Assim, evidencia-se durante a observação e nas falas dos participantes que a interdisciplinaridade não está 'pronta', nem pode ser reduzida a uma diretriz institucional. É um processo coletivo e que, no momento da pesquisa, foi percebido como 'em construção'. As dificuldades postas colocam a interdisciplinaridade como um desafio a ser perseguido pelas equipes, mas identifica-se que os profissionais compreendem a sua importância, conseguem se perceber no âmbito dos processos de cooperação e estabelecem esforços para que seja efetiva.

\section{Interdisciplinaridade como a realização de atividades em conjunto}

Eles acreditam (os profissionais) que as ações precisam ser ao mesmo tempo e que todos os profissionais precisam estar naquela atividade. (...) Eles acham que uma roda de conversa, uma sala de espera, só contemplaria a interdisciplinaridade se estivessem todas as categorias ali, e não é bem assim (2-Gestor - SER). 
Outro aspecto depreendido foi a compreensão da interdisciplinaridade como a realização de atividades em conjunto. Além das falas obtidas nas entrevistas, identificamos no processo de observação tal entendimento. A noção de que 'atuar em conjunto' é trabalho interdisciplinar aparece em alguns momentos de nossa pesquisa.

[A interdisicplinaridade] É o trabalho em conjunto enquanto uma área, uma profissão, uma área acaba entrando na outra e acaba se unindo pra um bem comum, né? Se unindo, cada área, cada profissional responsável por sua área, ele entra na área do outro e um ajudando o outro ( 2 - Terapeuta Ocupacional NASF).

Quando tem atividade conjunta, a gente articula para toda equipe participar (1- Assistente Social NASF).

O fato de atuarem de forma conjunta não garante a interdisciplinaridade. A colaboração interdisciplinar está no centro das discussões no âmbito das ciências e exige um esforço coletivo, no sentido de as diversas especialidades procurarem e encontrarem uma linguagem comum, entenderem as concepções iniciais e sob a forma de démarche conjugada e articulada, a fim de conseguirem aceitar o desraizamento provocado por problemáticas diferentes da sua (Japiassu, 1976).

Ao ser questionada sobre como se dá a interdisciplinaridade no NASF, a gestora enfatiza a necessidade de seu fortalecimento e expressa as dificuldades que observamos no cotidiano das práticas dos profissionais. O problema central, segundo ela, reside na sistematização do trabalho e na definição de papéis. O interdisciplinar, proposto por Morin (2011b) como a construção de pensamento integrado e da negação da 'hiperespecialização', é o desafio que se coloca. Não é uma questão de se confundirem os saberes, mas conjugá-los na busca da atenção integral proposta pela política pública. Um profissional na oficina de práticas grupais opina:

Fazer grupo só por fazer não é interessante. Necessário ter objetivos comuns. No manejo com grupos onde as práticas são mais subjetivas a contribuição dos assistentes sociais e psicólogos é muito importante (10 - Assistente Social - NASF).

Estudos de Scherer e Pires (2009) com equipes da ESF sobre a interdisciplinaridade já afirmavam que há dificuldades na integração dos diversos saberes. Enfatizavam que para a interdisciplinaridade acontecer seria necessário que cada profissional estivesse bem fundamentado em sua própria especialidade e na proposta do trabalho interdisciplinar. As referidas autoras vão destacar em sua pesquisa que o trabalho interdisciplinar também pode acontecer quando o profissional encontra-se sozinho, considerando que 
experiências anteriores de trabalho de grupo possibilitam connhecimento sobre métodos e abordagens de outras profissões. O que percebemos por meio da observação do contexto das oficinas é que essa partilha entre os saberes ainda é embrionária, explicitada claramente pelos profissionais, que atribuem principalmente ao processo de trabalho as dificuldades para o trabalho interdisciplinar.

Nesse sentido, necessário reiterar a análise, considerando que há uma grande distância entre o que realmente é um trabalho interdisciplinar da realização de atividades conjuntas entre profissionais que não se utilizam de suas especilidades para a concepção de uma proposta efetiva; quer seja em forma de prática educativa, quer seja na elaboração de projetos terapêuticos, apoio matricial ou outra atribuição que necessite de uma abordagem coletiva de caráter interdisciplinar. Estar em conjunto, em nossa análise, não abrange a condição de atuação coletiva interdisciplinar.

Todavia, a realidade que encontramos também denota outra percepção, considerando a representação social existente sobre o compromisso das equipes para o trabalho interdisciplinar, ou o que alguns estudos já realizados apontam como 'atitude interdisciplinar'.

\section{Interdisciplinaridade como resultado do compromisso profissional}

Não havia nenhuma ilha [expressão originada de uma dinâmica de grupo realizada na oficina sobre interdisciplinaridade]. Estávamos perdidos e sem rumo. A equipe decidiu fazer parceria, primeiro entre si, depois buscando apoio de alguns profissionais. A relação com coordenadores e equipes [de Saúde da Família] ainda é difícil, mas nós temos buscado os avanços (10 - Assistente Social - NASF).

Ao serem questionados sobre o trabalho em grupo e a interdisciplinaridade, os sujeitos revelaram importantes pistas para a compreensão do que Fazenda (2007) considera como uma 'questão de atitude', representação que se expressa na fala abaixo:

Na verdade eu vejo diferença entre o vínculo, o comprometimento de um profissional e outro. Porque no mesmo grupo que uns profissionais tão e outros parecem que não tão, entendeu? Mas eu acho também, eu não vou nem condenar, porque às vezes tem aqueles peixinhos que gostam de nadar contra a maré e tem aqueles que deixam a maré levar. Mas de quem é a culpa da maré tá contra? Eu acho que se a gente tivesse uma sistemática de trabalho organizada e profissionais com vínculo, eu acho que isso vem a melhorar (7 - Enfermeira - UBS).

Os profissionais refletem sobre essas dificuldades e compreendem que é necessário maior investimento pessoal para que haja o planejamento das ativi- 
dades em equipe, condição para o estabelecimento de relações interdisciplinares. As oficinas aconteceram por demanda dos próprios profissionais e não da gestão. Na avaliação final das oficinas o grupo utilizou expressões como 'braço amigo', 'luz no fim do túnel', 'apoio para a prática', 'empoderamento'.

No fragmento a seguir, encontramos suporte para essa interpretação:

O trabalho em grupo, né, a gente tem, é muito importante e é o que a gente trabalha, sempre em grupo. Mas a gente tem dificuldade porque o nosso NASF é apenas vinte horas, né? Então as quarenta horas, e tem outro grupo que trabalha vinte horas a partir da tarde, nós trabalhamos de manhã. Então nós temos essa dificuldade de nos reunir e de programarmos nosso mês, nossa semana. E fica, pra mim, eu acho que fica um trabalho incompleto, porque não tá o dia todo, não tá a equipe toda ( 2 - Terapeuta Ocupacional NASF).

Fazenda (2007) pressupõe que a interdisciplinaridade só possa ser atingida com a superação de barreiras e do abandono institucional de hábitos cristalizados, impondo às Ciências que compreendam seus limites e sua capacidade aproximativa, que jamais esgota a compreensão de toda a realidade.

Acerca das barreiras entre os sujeitos das equipes, Fazenda (2007) aponta que os obstáculos se encontram nos preconceitos, na falta de formação adequada e no comodismo. Assim, só mudanças efetivas no campo das relações sociais, psicológicas, culturais e materiais podem favorecer essa superação. Isso infere o uso de uma comunicação horizontal entre as ciências e uma formação profissional que valorize a interdisciplinaridade.

Desse modo, entende-se que a efetivação de práticas interdisciplinares requer, especialmente, a democratização das relações de poder no âmbito das equipes profissionais, reconhecendo dialeticamente a necessidade de saberes diferenciados para um mesmo objeto. Essa é apenas uma ponta do iceberg. A discussão acerca da interdisciplinaridade recai ainda sobre as formas de pensar e agir sob a ótica do individual e do coletivo, no contexto da sociedade contemporânea. Essa lógica do individual possui forte representação na fala de alguns membros das equipes:

O grupo NASF, assim, é difícil também pela falta de comunicação, de que a equipe é quebrada. Eles dizem que não, mas na verdade é que é. (...) São várias pessoas, e cada uma com seu jeito, acaba tendo quebra. (...) Então acaba que a gente atua cada uma ali do seu jeito. A gente não tem nenhuma orientação (11 - Farmacêutica-NASF)

A gente recebe muito 'despacho' com direcionamento para especialidades, principalmente da gestão e dos Agentes Comunitários de Saúde. E a gente vai fazendo, individualmente (12 - Fisioterapeuta - NASF - DC). 
A característica pautada no ranço das práticas eminentemente especializadas, baseada na fragmentação dos sujeitos e do foco voltado para a doença, impõe uma noção de globalidade do homem, exigindo que cada especialista ultrapasse os seus próprios limites, abrindo-se às contribuições de outras disciplinas (Sampaio, 2006). A autora recorre também a Japiassu (1976) e a sua categorização das práticas interdisciplinares e aponta algumas definições e discussões para a interdisciplinaridade, condição necessária ao trabalho no campo da saúde.

A interdisciplinaridade é uma relação de reciprocidade, de mutualidade, que pressupõe uma atitude diferente a ser assumida frente ao problema de conhecimento, isto é, substituir a concepção fragmentária pela unitária de sujeito (Sampaio, 2006, p. 82).

Scherer e Pires (2009), ao refletirem sobre a atitude dos sujeitos no trabalho, contribuindo para que a interdisciplinaridade aconteça, chamam a atenção para uma série de relações intersubjetivas, apontando limites e alternativas para que a atitude individual seja impulsionadora do projeto interdisciplinar. Os profissionais participantes deste estudo, apesar dos limites históricos, teóricos e institucionais impostos para a configuração atual dos NASF, procuram apoio, conversam entre si, incomodam-se, inquietam-se e querem fazer diferente, construindo paulatinamente o que as autoras classificam como "Entidades Coletivas Relativamente Pertinentes". São essas atitudes que reiteram a nossa convicção de que a interdisciplinaridade é necessária e possível no campo da saúde, no contexto da ESF e na sua vinculação com os NASF.

\section{Considerações finais}

Para construir a interdisciplinaridade no contexto das práticas profissionais realizadas no âmbito da ESF, em especial nos NASF, é preciso trazer para a reflexão as dificuldades oriundas dos encaminhamentos da gestão, a capacitação ainda insuficiente dos profissionais e a precarização das relações de trabalho, que constituem elementos que impactam negativamente na sua concretização. Contudo, as falas dos participantes deste estudo também denotam inúmeras possibilidades que se constroem no campo da saúde e que inspiram a superação da fragmentação dos múltiplos saberes que atuam na perspectiva coletiva.

São esses avanços que se estabelecem no cotidiano das práticas profissionais e repercutem na qualidade do trabalho desenvolvido por seres humanos, que se destina a outros seres humanos. É o trabalho vivo em ato 
(Merhy, 2007), espaço de micropolítica e de autogoverno, no qual insurgem possibilidades de romper com o que está posto e com as representações sociais presentes, possibilitando a construção de novos modelos de atuação profissional interdisciplinar. Tal perspectiva coaduna com o paradigma da complexidade, pois só é possível apreender o 'que é tecido junto' quando se supera o retalhamento das disciplinas (Morin, 2012). É o rompimento com a 'inteligência cega' (que destrói as totalidades e dicotomiza a relação entre o observador e o observado e que fraciona os problemas), apontada como o desafio dos desafios circunscritos à ciência. Considerando a saúde como campo científico de produção e reprodução de saberes, tal desafio é extremamente pertinente.

Importante ainda ponderar que no contexto do nosso estudo há uma forte motivação entre as equipes na busca pela qualificação profissional, procurando mudanças paradigmáticas com o que está instituído. Consideramos necessário que as reflexões já iniciadas que colocam a interdisciplinaridade como um 'processo em construção' sejam compartilhadas com todos que constroem a ESF (gestores e demais profissionais das equipes). Ainda é necessário que o NASF diga a que veio, assuma verdadeiramente seu papel matricial e seja apoio para a atenção à saúde na perspectiva integral posta para a ESF. Todavia, sabemos que esse movimento é repleto de contraditoriedades, reflexos das formações ainda superespecializadas e das influências que essa forma de pensar as ciências impõe a todos, indistintamente. $\mathrm{O}$ 'empoderamento' descrito pelas equipes na avaliação das oficinas de capacitação nos parece ser o fio condutor para que uma nova perspectiva de atuação aconteça.

Nesse contexto, parece-nos coerente propor no âmbito dos processos de educação permanente a discussão da interdisciplinaridade, promovendo um debate aprofundado, voltado para uma percepção teórico-crítica que possa promover uma efetiva partilha de saberes na construção de novas compreensões acerca dos processos de trabalho na saúde. Esse caminho pode viabilizar uma aproximação maior das áreas do conhecimento que hoje fazem parte da ESF, assegurando a efetividade de tecnologias e estratégias já costuradas na legislação e na literatura.

O NASF é um locus por excelência dessa produção de saberes, considerando sua formulação como dispositivo estratégico da ESF e de suas diretrizes, que são direcionadas a partir de uma perspectiva interdisciplinar e de matriciamento. Investir em um processo de formação profissional cada vez mais consistente e com um forte viés interdisciplinar é também ampliar as possibilidades de consolidação dos princípios propostos pela Atenção Primária em Saúde no Brasil. 


\section{Colaboradores}

Herta Maria Castelo Branco Ribeiro trabalhou na concepção e projeto de pesquisa, coleta, análise e interpretação dos dados, escrita e revisão crítica do conteúdo do artigo. Zeni Carvalho Lamy, Liduina Farias Almeida da Costa, Liberata Campos Coimbra trabalharam na concepção e projeto de pesquisa, análise e interpretação dos dados e revisão crítica do conteúdo do artigo. Lívia Janine Leda Fonseca Rocha, Dorlene Maria Cardoso de Aquino e Nair Portela Silva Coutinho trabalharam na redação e revisão crítica do conteúdo intelectual do artigo. Declaramos que não há conflito de interesses na elaboração do trabalho.

Resumen Este trabajo tuvo por objetivo analizar las representaciones sociales de profesionales de Núcleos de Apoyo a la Salud de la Familia de la Secretaría Ejecutiva Regional IV, en Fortaleza, Ceará, Brasil, sobre la interdisciplinaridad en su trabajo cotidiano. Se trata de un estudio cualitativo, que utiliza como técnicas de recolección de datos la observación participante y entrevistas semiestructuradas con 15 profesionales y coordinadores. En la definición de la muestra se utilizó el criterio de saturación teórica. En el análisis se utilizó la Hermenéutica de Profundidad. Las representaciones se organizaron en las siguientes categorías: proceso en construcción, realización de actividades conjuntas y resultado del compromiso de los equipos. Los caminos recorridos indican un interdisciplinaridad aun embrionaria, resultado de un sinnúmero de factores intrínsecos y extrínsecos al propio grupo. Las dificultades oriundas de las exigencias de productividad por parte de la gestión, la planificación incipiente, el proceso de formación que incorpora poco esta perspectiva y la precariedad de las relaciones laborales son elementos que afectan negativamente la realización de prácticas interdisciplinarias. Las expresiones denotan un sinnúmero de posibilidades que se construyen en el campo de la salud e inspiran la superación de la fragmentación de los múltiples saberes que actúan en la perspectiva colectiva.

Palabras clave atención primaria de la salud; núcleo de apoyo a la salud de la familia; interdisciplinaridad; representaciones sociales. 


\section{Notas}

1 Faculdade Metropolitana da Grande Fortaleza, Departamento de Serviço Social, Ceará, Brasil.

$<$ herta_ribeiro@hotmail.com>

Correspondência: Rua Ministro Eduardo Ellery Barreira, número 29 C, apartamento 601, Guararapes, CEP 60.810-010, Fortaleza, Ceará, Brasil.

2 Universidade Federal do Maranhão, Departamento de Saúde Pública, São Luís, Maranhão, Brasil.

<zenilamy@gmail.com>

3 Universidade Federal do Maranhão, Centro de Ciências da Saúde, Departamento de Enfermagem, São Luís, Maranhão, Brasil.

<liberata@uol.com.br>; <liberatacoimbra@gmail.com>

4 Universidade Estadual do Maranhão, Departamento de Educação e Filosofia, São Luís, Maranhão, Brasil.

<liviajrocha@gmail.com>

5 Universidade Federal do Maranhão, Centro de Ciências da Saúde, Departamento de Enfermagem, São Luís, Maranhão, Brasil.

$<$ dmcaquino@gmail.com>

6 Universidade Federal do Maranhão, Centro de Ciências da Saúde, Departamento de Enfermagem, São Luís, Maranhão, Brasil.

$<$ nairportelaufma@gmail.com>

7 Universidade Estadual do Ceará, Departamento de Serviço Social, Programa de Pós-Graduação em Políticas Públicas, Fortaleza, Ceará. Brasil.

$<$ liduinafariasac@gmail.com>

8 A pesquisa constitui-se resultado de dissertação de mestrado em Saúde da Família intitulado "Representações sociais sobre a interdisciplinaridade: percepções das equipes multiprofissionais dos Núcleos de Apoio à Saúde da Família" realizado na Nucleadora Universidade Federal do Maranhão (UFMA) da Rede Nordeste de Formação em Saúde da Família (RENASF), de autoria de Herta Maria Castelo Branco Ribeiro.

\section{Referências}

BRASL. Ministério da Saúde. Diretrizes do NASF: Núcleo de Apoio à Saúde da Família. Cadernos de Atenção Básica, n. 27. Brasília: MS, 2010.

BRASIL. Ministério da Saúde. Portaria GM n. 2.488 , de 21 de outubro de 2011. Aprova a Política Nacional de Atenção Básica, estabelecendo a revisão de diretrizes e normas para a organização da Atenção Básica para o Programa Saúde da Família (PSF) e o Programa Agentes Comunitários de Saúde (PACS). Brasília: MS, 2011. 
BRASIL. Ministério da Saúde. Portaria GM/3.124 de 28 de dezembro de 2012. Redefine os parâmetros de vinculação dos Núcleos de Apoio à Saúde da Família (NASF) Modalidades $1 \mathrm{e}$ 2 às Equipes Saúde da Família e/ou Equipes de Atenção Básica para populações específicas, cria a Modalidade NASF 3, e dá outras providências. Brasília: MS, 2012.

BRASIL. Departamento de Informática do SUS. CNES: Cadastro Nacional de Estabelecimentos de Saúde. Disponível em: <www. datasus.saude.gov.br/sistemas-e-aplicativos/ cadastros-nacionais/cnes>. Acesso em: 23 dez. 2013.

DEMO, Pedro. Hermenêutica de profundidade, à La Thompson. In: DEMO, Pedro. Pesquisa e informação qualitativa: aportes metodológicos. São Paulo: Papirus, 2012. p. 35-48.

FAZENDA, Ivani C. A. Interdisciplinaridade: um projeto em parceria. São Paulo: Edições Loyola, 2007.

FAZENDA, Ivani C. A. Interdisciplinaridade: história, teoria e pesquisa. São Paulo: Papirua, 2012.

FERREIRA, Darlisom S. A Teoria das Representações Sociais: um caminho para o estudo de práticas educativas com idosos amazônidas. In: TEIXERA, Elizabeth (Org.). Abordagens qualitativas: trilhas para pesquisadores em saúde e enfermagem. São Paulo, Martinari, 2008, p. 121-134.

FONTANELLA, Bruno J. B.; MAGDALENO JUNIOR, Ronis. Saturação teórica em pesquisas qualitativas: contribuições psicanalíticas. Psicologia em estudo, Maringá, 2012, v. 17, n. 1, p. 63-71.

FRANCO, Túlio; MERHY, Emerson E. Programa de Saúde da Família: contradições de um programa destinado a mudança do modelo tecnoassistencial. In: MERHY, Emerson E. et al. Trabalho em saúde: olhando e experienciando o SUS no cotidiano. São Paulo: Hucitec, 2007. p. 55-124.
JAPIASSU, Hilton. Interdisciplinaridade e patologia do saber. Rio de Janeiro: Imago, 1976.

KRUG, Suzane B. F. et al. O processo de trabalho na Estratégia de Saúde da Família: o que dizem os profissionais de saúde em Santa Cruz do Sul/RS. Textos e Contextos, Porto Alegre, v. 9, n. 1, p. 77-88, jan./jun. 2010.

LEITE, Rosana F. B.; VELOSO, Thelma M. G. Trabalho em equipe: representações sociais de profissionais do PSF. Revista Psicologia: Ciência e Profissão, Brasília, v. 28, 2008. Disponível em: <www.scielo.br/scielo. php? pid $=$ S1414-98932008000200012\& script=sci_arttext>. Acesso em: 23 dez. 2012.

LÉVINAS, Emmanuel. Ensaios sobre alteridade. Petropólis: Vozes, 1997.

MERHY, Emerson E. Um dos grandes desafios para os gestores do SUS: apostar em novos modelos de fabricar os modelos de atenção. In: MERHRY, Emerson E. et al. Trabalho em saúde: olhando e experienciando o SUS no cotidiano. São Paulo: Hucitec, 2007. p. 15-35.

MINAYO, Maria C. S. O desafio do conhecimento: pesquisa qualitativa em saúde. São Paulo: Hucitec, 2013.

MORIN, Edgar. Os sete saberes necessários à educação do futuro. São Paulo: Cortez, 2011 la.

MORIN, Edgar. Introdução ao pensamento complexo. Porto Alegre: Sulina. 2011 b.

MORIN, Edgar. A cabeça bem-feita: repensar a reforma, reformar o pensamento. Rio de Janeiro: Bertrand Brasil, 2012.

REIS, Valéria M.; DAVID, Helena M. S. L.O fluxograma analisador nos estudos sobre processo de trabalho em saúde: uma revisão crítica. Revista APS, Juiz de Fora, v. 13, n. 1, p. 118-125, jan./mar. 2010.

ROSSONI, Eloá; LAMPERT, Jadete. Formação profissional para o Sistema Único de 
Saúde e as Diretrizes Curriculares. Boletim da Saúde, Porto Alegre, v. 18, jan./jun. 2004.

SAMPAIO, Cláudia C. Interdisciplinaridade em questão: análise de uma política de saúde voltada à mulher. In: SÁ, Jeanete L. M. (org). Serviço Social e interdisciplinaridade: dos fundamentos filosóficos à prática interdisciplinar no ensino, pesquisa e extensão. São Paulo: Cortez, 2006. p. 77-95.

SCHERER, Magda D. A.; PIRES, Denise. A interdisciplinaridade prescrita para o trabalho da equipe de saúde da família, na percepção dos profissionais de saúde. Tempus: Actas de Saúde Coletiva, Brasília, v. 3, n. 2, 2009. Disponível em: <www.tempusactas. unb.br/índex.php/tempus/article/viewfile/ 730/739>. Acesso em 10 out. 2011.

SEVERINO, Antônio J. Subsídios para uma reflexão sobre novos caminhos da interdisciplinaridade. In: SÁ, Jeanete L. M. (Org). Serviço Social e interdisciplinaridade: dos fundamentos filosóficos à prática interdisciplinar no ensino, pesquisa e extensão. São Paulo: Cortez, 2006. p. 11-20.
SOUZA, Fernanda R. Processo de construção dos núcleos de apoio à saúde da família (NASF) na atenção básica do estado do Ceará. 2013. 220f. Dissertação (Mestrado em Saúde Pública) - Faculdade de Medicina, Programa de Pós-graduação em Saúde Coletiva, Fortaleza, 2013.

VASCONCELOS, Eduardo M. (Org). Saúde mental e serviço social: o desafio da subjetividade e da interdisciplinaridade. São Paulo: Cortez, 2002.

Recebido em 16/06/2014

Aprovado em 06/04/2015 